\title{
La investigación de mercado: una ventana a nuestra sociedad
}

\section{Market Research: A Window Into our Society}

\author{
Alicia Pinzás Stoll \\ Universidad de Lima
}

\section{RESUIMEN}

La información recogida a través de una larga experiencia de investigación de mercado y de opinión pública ofrece pistas para entender el surgimiento de los nuevos sectores medios urbanos, diferentes a las clases medias tradicionales, en el Perú de los últimos años, marcado por las tensiones no resueltas en el camino entre la tradición y la modernidad. Se describen algunos factores que contribuyen al surgimiento de estos sectores: el emprendimiento en un contexto informal y la valoración de la educación, a pesar de sus deficiencias, como un importante medio de movilidad social. El consumo como un indicador de inclusión y democratización, así como la información globalizada, que se ha convertido en el referente virtual que construye sus expectativas gracias a las nuevas tecnologías, son fundamentales en el desarrollo de estos nuevos actores sociales. Resalta en este proceso el rol protagónico que cumplen las mujeres que, incorporadas al emprendimiento y al consumo, avanzan en su autonomía económica y en su empoderamiento a pesar de las trabas que todavía existen en el país para la igualdad de género, y que obliga a una redefinición del rol masculino en la pareja y en el hogar.

\section{Palabras clave:}

Investigación de mercado / Consumo / Modernidad / Emprendimiento / Nuevos sectores medios / Género

\section{ABSTRACT}

The information gathered through a long experience in market research and public opinion offers clues to understand the emergence of new urban middle sectors, different from the traditional middle classes in Peru in recent years, marked by unresolved tensions between tradition and modernity. Some factors that contribute to the emergence of these sectors are described in this paper: entrepreneurship in an informal context and the valuation of education, despite its deficiencies, as an important means of social mobility. Consumption as an indicator of inclusion and democratization, as well as globalized information, which has become the virtual benchmark that builds its expectations thanks to the new technologies, are fundamental in the development of these new social actors. In this process, the key role played by women who - incorporated into entrepreneurship and consumption - are advancing in their economic autonomy and empowerment despite the obstacles that still exist in the country for gender equality, which forces a redefinition of the male role in the couple and in the home.

Keywords:

Market Research / Consumption / Modernity / Entrepreneurship / New Middle Sectors / Gender 
$E^{\prime}$ trabajo que he venido desempeñando como consultora cualitativa en investigación de mercado y de opinión pública ${ }^{1}$ durante más de veinte años, interactuando con mujeres, hombres y jóvenes de distintas regiones del Perú y de todos los niveles socioeconómicos, me sirve como una ventana desde la que me asomo a observar las transformaciones que la realidad social ha sufrido en las últimas décadas, especialmente las percepciones que de ella tienen los propios actores sociales protagonistas de estos cambios. Entre estas transformaciones, el surgimiento de una nueva clase media, conformada por las generaciones que tienen sus raíces en las migraciones rurales hacia las ciudades de las décadas anteriores, ha merecido especial atención de la investigación de mercado debido a su consolidación como los principales consumidores del siglo XXI.

Además, desde esta ventana he observado los recientes procesos electorales y el cambio de énfasis en los ofrecimientos de campaña que lograron eco en la población al punto de incorporar en el vocabulario corriente del momento términos cargados de connotaciones mayoritariamente positivas, pero no definidos con precisión. Entre ellos, destacan la promesa de "transformación" e "inclusión", eje de la campaña de Ollanta Humala en el 2011, y el ofrecimiento de llevar el país a la "modernidad", que aparece con fuerza a partir de la victoria de Peruanos por el Kambio en la segunda vuelta electoral del 2016. Es sobre esta experiencia que quisiera reflexionar en este ensayo.

\section{Las nuevas clases medias y la modernidad}

En el 2013 llamó fuertemente la atención la difusión de un informe del BID (Jaramillo y Zambrano, 2013) que generó una reacción que osciló entre el entusiasmo y el escepticismo. Los medios de comunicación se convirtieron en voceros de las conclusiones de este informe: el Perú se había convertido en un país donde las clases medias eran mayoritarias, un país "de ingresos medios". Esta afirmación se sustentaba en una definición de clase media en función del ingreso, según la cual a partir de un ingreso de cuatro dólares diarios la población deja de ser pobre y se incorpora a "las clases medias emergentes" y a partir de diez dólares diarios pasa a engrosar las filas de la clase media².

A partir de este anuncio del BID, se generó un prolongado debate, especialmente entre los especialistas más connotados de la investigación de mercado, que la revista Semana Económica difundió en sus páginas. Por un lado, Rolando Arellano ratificó las afirmaciones del $\mathrm{BID}$, reconociendo como clase media a un $57 \%$ de la población peruana, pues esta cuenta con "capacidad discrecional" para elegir su consumo y para invertir, su vulnerabilidad sería muy relativa pues en los últimos años ha presentado claras muestras de progreso, y porque, además, se autopercibe como clase media, aunque diferente a la clase media tradicional. Por otro lado, Alfredo Torres hizo notar que si se incluye en el análisis a la población rural y de las pequeñas ciudades del interior y no solo a la población de las ciudades más importantes, las cifras contradicen los resultados del BID. Es cierto que se observa un crecimiento de una nueva clase media en el Perú en su conjunto (clase media que podría corresponder a los NSE B y C en uso en la investigación de mercado) que ha pasado de $22,5 \%$, en 2005 , a $32,5 \%$, en $2012^{3}$, y también que en las ciudades con más de doscientos mil habitantes IOS NSE B y C alcanzan el $51,4 \%$; sin embargo, si consideramos solo las aglomeraciones con menos de doscientos mil habitantes, este porcentaje se reduce al $14,4 \%$ y los NSE D y E (que corresponden a sectores pobres) llegan al $85,4 \%$, en esa misma fecha ${ }^{4}$.

Coincido con Arellano en que estas nuevas clases medias urbanas muestran diferencias significativas con la clase media tradicional desde el punto de vista cultural: sus raíces se encuentran en la migración provinciana, de origen, sobre todo, rural y andino; sus barrios se ubican en la periferia de la ciudad; su estilo de vida no imita al de las clases altas. Pero, personalmente, considero que no podemos mostrarnos excesivamente optimistas. La realidad que observamos a través

1 La investigación de mercado es un tipo de investigación aplicada que permite a las empresas tomar mejores decisiones de marketing, gracias a un mayor conocimiento acerca de sus consumidores. Mi experiencia de trabajo en este campo se ha desarrollado como consultora cualitativa en la empresa Apoyo Opinión y Mercado, que luego devino en Ipsos-Perú. Las metodologías cualitativas que utiliza Ipsos-Perú ponen el foco en las personas como sujetos situados en un contexto cultural determinado en el tiempo y en el espacio, con necesidades, percepciones y motivaciones que se traducen en hábitos de consumo y opiniones sobre la realidad social y política particulares.

2 En la polémica que se generó a partir de la publicación de este informe del BID, se utiliza el concepto de "clases medias" que se retoma en este ensayo; sin embargo, su definición no corresponde a la visión académica de las ciencias sociales, sino que se apoya en el concepto de "nivel socioeconómico" que utiliza la investigación de mercado más próximo al de estrato de las ciencias sociales. Los niveles socioeconómicos se determinan, según las empresas peruanas de investigación de mercado, agrupadas en la APEIM, por un conjunto de variables como las características del jefe de hogar (su nivel educativo, su ocupación), las características de la vivienda y el consumo y posesión de bienes y servicios de la familia. A partir de estos datos, los segmentos que se etiquetan como "clases medias emergentes" corresponden a los NSE B2 y C1 en uso en la investigación de mercado en nuestro medio.

3 Fuente: Ipsos-Perú, a partir de INEI-ENAHO, APEIM, 2005 y 2013.

4 Fuente: Ipsos-Perú, a partir de APEIM 2013. 
del trabajo de campo nos muestra la extrema vulnerabilidad de estas nuevas clases medias ante cualquier situación de crisis personal, familiar 0 política. Igualmente, la autopercepción como clase media de estos sectores responde, en gran medida, a su fuerte aspiracionalidad, y no siempre corresponde a la realidad. Además, como lo muestran las cifras que sustentan las afirmaciones de Torres, los índices de desigualdad se han reducido de manera todavía insuficiente ${ }^{5}$ para garantizar la estabilidad política y la gobernabilidad democrática ${ }^{6}$ que podría esperarse en un país de ingresos medios.

En este contexto, la campaña de Ollanta Humala que ofrecía promover una "gran transformación" social, orientada a la "inclusión", caló hondamente en la ciudadanía, especialmente de las zonas más desfavorecidas —ámbito rural y ciudades pequeñas del interior del país - y determinó su triunfo en la segunda vuelta de las elecciones de 2011, así como la decepción posterior de sus electores, que no perciben avances significativos en este ámbito. El concepto de inclusión pasó a formar parte del imaginario de la población, a tal punto que fue utilizado en la publicidad de las empresas, y las campañas que se apoyaron en él y que apelaron a la identidad peruana popular tuvieron gran éxito en todos los segmentos sociales. Resaltan, entre las que tuve oportunidad de evaluar, la campaña de imagen de Movistar de 2009, que utilizó referencias literarias inspiradoras (Vallejo, Vargas Llosa) para acercarse a la población con un mensaje de progreso, unión y optimismo; asimismo, una campaña del BCP, iniciada en 2008 , que se dirigía a los pequeños empresarios a través de un personaje icónico de lo andino y lo popular: el cuy mágico.

Es en estas nuevas clases medias, surgidas en los últimos años, que se pueden observar más claramente las tensiones no resueltas en el camino entre la tradición y la modernidad. Para profundizar más en este tema intentaremos definir la modernidad según algunas posiciones académicas y, luego, puntualizar cuál es la concepción de modernidad de nuestra clase política y de estas nuevas clases medias.

Hay consenso en las ciencias humanas en que el término "modernidad" es muy polisémico y poco preciso. Giddens (1990) nos presenta un análisis de este concepto del que tomaremos las ideas que siguen. En primer lugar, el término se utiliza para tipificar a las sociedades que surgen en occidente a partir de siglo XVII y que adquieren un modo de vida que posteriormente se globaliza. Actualmente, se acostumbra asociar modernidad con una sociedad donde prima el consumo y la información, al punto de que los derechos y deberes de los ciudadanos han devenido en los de los consumidores y que las tecnologías comunicativas han sufrido una revolución extraordinaria, con consecuencias que "se están radicalizando y universalizando como nunca" (Gidens 1990, p. 17). Así, la modernidad, tal como la define Giddens, implica pasar de las interacciones cara a cara, basadas en el parentesco y en los intercambios dentro de una comunidad local, a la interacción anónima y fugaz con sistemas expertos cada vez más desanclados del espacio y el tiempo locales: instituciones globales, sistema financiero, medios de comunicación masivos, Internet. Esta modernidad permite la integración en comunidades globalizadas enlazadas a distancia, y transforma la valoración de la estabilidad de la tradición en la adopción de ritmos dinámicos, orientados al futuro.

El impulso de los procesos modernizadores (industrialización, urbanización, desarrollo de la comunicación y del transporte, globalización de las econo- mías), que identifica Mabel Moraña, le permite definir modernidad como un "paradigma cultural, es decir, como el conjunto de condiciones materiales que, a partir de una ruptura, a veces violenta con las formas de vida tradicionales, da como resultado un estado de la cultura y el pensamiento que cambia los imaginarios, expectativas y comportamientos sociales"7 que se irradian desde los centros hegemónicos de Europa y Estados Unidos pero se adaptan a las realidades locales.

En nuestro caso, aunque durante la reciente campaña presidencial no se usó el concepto de "modernidad" como idea fuerza, una vez confirmada la elección del nuevo gobierno, para el periodo 2016-2021, la promesa de llevar al Perú a la modernidad comenzó a aparecer entre la clase política y llegó a la opinión pública. Al asumir funciones el nuevo gobierno, este pareció consciente de que era necesario dotar de contenido a este término polisémico e impreciso; comenzó así a definir modernidad como la construcción de un país más competitivo y menos desigual. La modernidad queda así definida esencialmente en términos económicos — situando los esfuerzos necesarios en este ámbito en el contexto de una economía globalizada-, pero reconoce implícitamente que, para ello, es también necesaria la inclusión de todos los peruanos en el proyecto nacional, objetivo que todavía estamos lejos de lograr.

Esta conceptualización de la modernidad que se desea para el país alcanzó su mayor precisión en el discurso de Pedro Pablo Kuczynski en la ceremonia de investidura del 28 de julio de 2016. El nuevo presidente ofreció un discurso didáctico, en el que compartió su visión de país, cuyo eje fue el acceso a la modernidad, concepto en el que incluyó todas las aspiraciones y

5 En 1986, según el Banco Mundial, el índice Gini de igualdad alcanzaba el 0,46; en el año 2005 la desigualdad no se había reducido, al contrario, había aumentado (índice Gini 0,51), aunque luego se logró una cierta reducción a partir del año 2010.

6 Sanahuja (2015) observa este fenómeno de manera general en las nuevas clases medias que han ido surgiendo en los países emergentes.

7 Mabel Moraña (Itinerarios, 2007) en varios artículos y libros se interesa en el concepto de modernidad, especialmente en el Perú, a través de sus escritores. 
necesidades recogidas de la población. La visión que nos propone Kuczynski del país moderno "que todos anhelan" es la de un país sin desigualdades en el acceso a los servicios esenciales, desde la salud hasta la tecnología; de un país honesto, con justicia y sin corrupción; de un país sin discriminación por raza o por género, educado, seguro, conectado al mundo, respetuoso del medio ambiente y económicamente competitivo; además de consolidarse como una democracia reconocida a nivel internacional ${ }^{8}$.

Por su parte, los actores sociales, integrantes de las nuevas clases medias, protagonistas de las sesiones grupales y entrevistas que he realizado como parte de la investigación de mercado, conceptualizan la modernidad esencialmente como "cambios positivos" en su acceso al consumo, en su vida personal y en su entorno social, y sus eventuales críticas se orientan sobre todo a su percepción de que esta es una vaga promesa de los políticos y que para ellos las oportunidades de formar parte de estas transformaciones son insuficientes. Por ello, estimo que la modernidad, tal como la definió el flamante presidente, sintoniza con el imaginario de las aspiraciones de estas nuevas clases medias urbanas, cuya identidad cultural, en relación con el trabajo, el esfuerzo, sus expectativas frente al Estado y sus hábitos de consumo, se diferencia de las clases medias tradicionales, especialmente limeñas, y se ha ido construyendo en razón de los factores que han permitido y que van consolidando su surgimiento.

\section{Factores que} intervienen en el surgimiento de las nuevas clases medias

\section{Consumo y emprendimiento como motores del progreso}

Julián tiene 35 años $y$ vive en El Agustino. Nació en 1981, en Junín, en la Ceja de Selva, donde ayudó en la chacra de sus padres hasta que migró a Lima siguiendo a sus hermanos mayores que habían huido de la violencia. Trabajó en La Parada, con paisanos que comercializaban frutas $y$ verduras; vivía con sus hermanos $y$ llegó a terminar la secundaria. Trabajando como ambulante en la puerta de un mercado, logró formar un capital y comenzó a viajar a su tierra y a traer los productos que sembraban sus padres, especialmente ají y rocoto. Fue progresando, buscando oportunidades y hoy se ha especializado en la comercialización del rocoto para varias cadenas de supermercados. Sus padres y otros paisanos de la zona son sus proveedores, ha invertido en dos vehículos de carga gracias a un préstamo bancario para pequeñas empresas y sueña con exportar a mercados que valoran los productos naturales que contribuyen al éxito de la gastronomía peruana en el mundo. Utiliza su tarjeta de crédito para aprovechar las ofertas de los supermercados y para adquirir artefactos en varias cuotas.

El consumo es un aspecto central de la cultura de la modernidad a la que estas nuevas clases medias se han volcado con entusiasmo. La variedad y cantidad de productos y marcas que se ofrecen al consumidor actual, frente a la precariedad de una historia familiar cercana y de las restricciones que vivió el país en épocas que las generaciones maduras todavía recuerdan, confortan al ciudadano en su idea de que el país está progresando y que todos podemos ser parte de este progreso. En el imaginario de la mayoría de estos actores sociales, la aparición de los nuevos espacios de consumo — cadenas de supermercados y centros comerciales- son las primeras señales de que la modernidad y la inclusión están llegando a todos los peruanos. Llama la atención que la efectivización de la inclusión —antes que en intervenciones del Estado sobre el espacio público- se perciba en las propuestas privadas comerciales. Pero las razones son claras para estos consumidores: la arquitectura y la disposición de los espacios interiores (amplios pasillos, limpieza e iluminación, carritos de compra, estantes que ofrecen los productos en libre servicio, profusión de productos y marcas, variedad de precios) y la accesibilidad a las tarjetas de crédito son una prueba tangible de democratización: el centro comercial de San Isidro es igual al de Lima Norte y al de una ciudad provinciana; 9 del mismo modo que la navegación por el mundo virtual de las páginas web en las que las empresas promocionan sus productos no tiene barreras de ningún tipo. Así, la frecuentación de estos espacios reales y virtuales, aunque en ellos solo se adquieran productos de primera necesidad que se encuentran en oferta, permiten prácticas asociadas a la vida moderna: uso de sistemas de crédito, prioridad por alimentos envasados (yogurt, gaseosas, snacks), hábitos de utilización de productos prácticos (pañales descartables, toallitas húmedas).

Sin embargo, estos espacios de modernidad conviven con los mercados tradicionales, que siguen siendo lugares de consumo privilegiados, pues cumplen también el rol de importantes espacios de interacción, especialmente de las amas de casa, donde estas comparten saberes y formas de reciprocidad. En los mercados de los barrios son posibles compras de muy pequeñas cantidades e, incluso, compras a cré dito de ropa 0 artefactos con pequeños pagos semanales, basadas en un contrato de confianza.

El héroe moderno de estas nuevas clases medias es el emprendedor. En

8 Discurso de investidura como presidente de la república del 28 de julio del 2016. 
los últimos años, el sueño del negocio propio atraviesa todos los sectores sociales. Los modelos de éxito a través de emprendimientos que han llevado a vendedores ambulantes, bodegueros 0 pequeños productores a construir grandes empresas familiares que han triunfado, incluso en el extranjero, ha posibilitado una imagen del emprendedor peruano como creativo, luchador, capaz de fracasar y levantarse nuevamente: los Wong, los Añaños y muchos pequeños empresarios anónimos forman parte de esta saga de emprendedores que tienen que luchar contra la preferencia que se le atribuye al Estado por las grandes transnacionales extranjeras.

Aunque el sistema financiero ha contribuido con algunos de estos proyectos, la bancarización en el país es todavía mínima en comparación a otros países de la región ${ }^{10}$ y ha participado muy poco en estos emprendimientos. En efecto, un sistema financiero que exige garantías formales no responde a las necesidades de este gran sector que ha surgido dentro de parámetros informales —flexibles, basados en la confianza interpersonal-que explican en gran medida las razones de su éxito. Por otro lado, estos sectores muestran una gran desconfianza con las instituciones, en general por lo que su progreso se sustenta esencialmente en relaciones propias de la informalidad: vínculos de parentesco en el contexto de una familia amplia, relaciones de paisanaje y relaciones personales de confianza con patrones que apadrinan un proyecto de negocio.

\section{Peruanos \\ más educados $y$ conectados al mundo}

Vilma tiene 32 años. Sus padres, migrantes de la Sierra Norte, se instalaron en Los Olivos, donde trabajaron primero como ambulantes y luego consiguieron un pequeño puesto en el mercado. Cuando la conocimos, estaba a punto de terminar su carrera de administración en Universidad Nacional Mayor de San Marcos, gracias a que sus padres, con mucho sacrificio, la apoyaban; ella colaboraba en el mercado los fines de semana. Cuando la volvimos a ver, ocho años más tarde, nos contó que al terminar sus estudios comenzó a trabajar en una empresa bastante importante, lo que le permitió ahorrar para hacer una maestría en una universidad privada. Este diploma y los contactos que consiguió durante sus estudios le abrieron las puertas de una transnacional donde se desempeña como responsable del área de recursos humanos. Además, está comenzando un negocio propio de servicio de taxis con su esposo que actualmente trabaja como taxista con un vehículo que Vilma adquirió a través de un crédito. Siguen viviendo en el mismo barrio, pero ha podido ampliar su vivienda y comprar los aparatos tecnológicos más modernos.

Una de las principales aspiraciones que caracteriza a estos sujetos sociales es lograr, especialmente para sus hijos, estudios universitarios que los convertirán en profesionales, pues se percibe la educación como un importante medio de movilidad social, por lo que la educación formal ha crecido significativamente en las últimas décadas ${ }^{11}$. Ante la percepción generalizada de la mala calidad de la educación pública, la oferta educativa privada, desde la educación inicial hasta la universitaria, se ha incrementado desmesuradamente en todos los niveles socioeconómicos y, a pesar de los bajísimos estándares de calidad de gran parte de esta oferta educativa, estos sectores emergentes con grandes aspiraciones de progreso pero sin criterios suficientes para evaluarla adecuadamente, la prefiere al sistema estatal.

A falta de mejores criterios, una infraestructura identificada como moderna (edificios, lunas polarizadas, espacios cuidados y sus respectivos guardianes uniformados) y que se acerca a estos usuarios ubicando sus locales en los barrios de la nueva Lima, contribuirán a construir una imagen positiva de la formación que se ofrece en estos establecimientos.

Gracias a las nuevas tecnologías de la comunicación, que han penetrado masivamente en el país, actualmente el mundo global, desanclado de los espacios físicos, es el referente virtual a partir del cual estos grupos sociales evalúan su realidad y construyen sus expectativas. Con ellas, se refuerza la convivialidad a distancia, se facilita la conformación de comunidades de intereses a través de las redes sociales, al punto de que estas pueden lograr movilizaciones ciudadanas que ya no consigue la política tradicional. Así, ante problemáticas sociales y políticas, las redes sociales (y en ellas, particularmente los jóvenes nativos digitales) han sido muy activas y eficaces para lograr objetivos importantes ${ }^{12}$ : el colectivo No a Keiko ha conseguido movilizar a una amplia variedad de ciudadanos y cerrar el paso a la candidatura de Fuerza Popular; más recientemente, la campaña Ni Una Menos ha obtenido el apoyo generalizado de los sectores más diversos para frenar la violencia contra la mujer.

Estos aspectos positivos del uso de la tecnología no nos deben hacer olvidar

9 Este tipo de arquitectura corresponde a lo que Augé (1992) llama "no lugares", es decir, lugares propios de la modernidad que no pueden definirse a partir de una identidad, de un tipo de relaciones o de una historia particular.

10 Para el año 2015 se estima que el 51 \% de limeños sería cliente de alguna entidad financiera (Ipsos-Perú, Bancarización del limeño, Lima Metropolitana, 2015), porcentaje que se reduce significativamente en el resto del país.

11 La población mayor de 15 años de edad ha completado, según cifras del 2014, algo menos de diez años de escolaridad, en el caso de las mujeres, y algo más de diez años, en el caso de los hombres (INEI, 2015).

12 Fernández Maldonado y Navarro (2016) describen en un reciente artículo esta nueva forma de movilización ciudadana en la que los nativos digitales lideran acciones colectivas a través de las redes sociales, a las que podemos sumar la reciente marcha contra la violencia hacia la mujer del 13 de agosto de este año. 
su lado negativo: la televisión basura se ha convertido en el referente de éxito y de valores, sobre todo entre los jóvenes y niños de estas nuevas clases medias. Asimismo, la conectividad virtual se impone sobre las relaciones cara a cara.

\section{El empoderamiento de las mujeres: nuevas relaciones entre los géneros}

Dina tiene 37 años, nació en la sierra sur y vino a Lima jovencita a trabajar como empleada doméstica. Mientras trabajaba terminó su secundaria y salió embarazada de su primer hijo, que hoy tiene 15 años. La relación no funcionó, y ya con su hijo comenzó a trabajar como ambulante y conoció a su actual esposo, que trabaja como albañil, con quien tiene un hijo de 8 años. Sueña con que sus hijos sean profesionales y tengan más oportunidades que las que ella tuvo, por lo que se esfuerza cada día. Actualmente, en la casa que construyeron en la zona alta de Villa María del Triunfo, Dina tiene una pequeña bodega, donde ofrece productos de belleza porque es consultora de varias empresas de cosméticos; además, siguió cursos de cosmetología y piensa abrir pronto una peluquería. Es dirigente de su asentamiento porque quisiera que en su barrio mejoren los servicios, las pistas y la seguridad.

El protagonismo actual de las mujeres en casi todos los ámbitos de actividad y que llama tanto la atención no parece ser una novedad en nuestro medio. Ya Flora Tristán, después de su viaje al Perú entre 1833 y 1834, afirmaba: "las mujeres de Lima gobiernan a los hombres porque son muy superiores a ellos en inteligencia y en fuerza moral..." (2003, p. 388). Del mismo modo, mi abuela, que migró a Lima desde su ciudad andina en 1918, acompañando las ambiciones de su marido, fue una mujer empoderada que mostró una férrea voluntad para sacar adelante a sus ocho hijos, pero sin dejar nunca de ser una señora de su casa, una esposa dedicada y fiel, con sus valores y prejuicios intactos.

Actualmente, en cambio, la mujer, además de reconocerse como el motor que saca adelante a la familia, especialmente a los hijos, se define como emprendedora, capaz de valerse por sí misma, menos conformista que el hombre al que ya no considera indispensable para salir adelante ${ }^{13}$ Esta autopercepción obliga a su vez a la redefinición de la identidad masculina, proceso que están llevando a cabo los jóvenes que comienzan a participar activamente en las tareas del hogar y no imponen sus decisiones unilateralmente, pero que genera mucho malestar entre los mayores. Otro ámbito de avances significativos es la planificación familiar: las mujeres son proactivas en la limitación del número de hijos y su mayor espaciamiento ${ }^{14}$.

El empoderamiento de las mujeres es particularmente notable en tanto consumidoras: se consideran las expertas en el manejo del hogar y son reconocidas como tales por el esposo y los hijos, administradoras que saben sacar el mejor provecho de presupuestos limitados, compradoras informadas que buscan ofertas y la mejor relación calidad-precio. Del mismo modo, incursionan con gran fuerza en los pequeños negocios que ofrecen flexibilidad, les permiten seguir ocupándose de las tareas domésticas y les generan ingresos que contribuyen con su empoderamiento: consultoras de belleza, venta de comida, comercio ${ }^{15}$. Las menores de cincuenta años y, en particular, las más jóvenes, sacan partido de las tecnologías de la comunicación más recientes, que utilizan para supervisar los movimientos de todos los integrantes de la familia, controlar la comida de los hijos y el avance de sus tareas, pero también para actividades laborales como la comunicación con sus jefes, sus colegas, sus clientes y sus proveedores.

Las heroínas de esta nueva identidad femenina son las mujeres que han alcanzado el éxito por sí mismas en los ámbitos más atractivos y más presentes en los medios de comunicación masivos. Deportistas, actrices, profesionales que triunfan en el extranjero, como Kina Malpartida, Sofía Mulánovich, Magaly Solier; pero también, intérpretes de cumbia ${ }^{16}$, conductoras y concursantes de programas televisivos que simbolizan la fuerza femenina y el enfrentamiento con los hombres maltratadores, dejando atrás una vida precaria, experiencias de violencia, embarazos tempranos, y que logran la simpatía del público y el bienestar económico para su familia sin olvidar sus orígenes humildes, manteniendo su sencillez y su estilo popular. Es sintomático que entre los candidatos a la elección presidencial de 2016, dos mujeres, que representan opciones ideológicas opuestas, se hayan ubicado en las tres primeras posiciones.

Estas mujeres ya no quieren ser representadas en roles tradicionales y rechazan el paternalismo. Así, en una reciente evaluación publicitaria con

13 En la actualidad, $31 \%$ de los jefes de hogar son mujeres contra 26 \% en 2005 (Fuente: Ipsos-Perú, Perfil del ama de casa 2015).

14 Más del $50 \%$ de mujeres unidas entre los 15 y los 49 años estaría utilizando un método anticonceptivo moderno y un $20 \%$ un método tradicional. (Fuente: INEI, 2015, Encuesta demográfica y de salud familiar).

15 El 77 \% de los bodegueros de Lima Metropolitana son mujeres. (Fuente: Ipsos-Perú, Perfil de las bodegas 2012).

16 Entre otras intérpretes femeninas, resalta Marisol, La faraona de la cumbia, que generó gran identificación a través de una telenovela que se inició en 2012. 
un grupo de pequeños empresarios emergentes, las participantes consideraron machista una pieza gráfica porque representaba a una comerciante en un negocio tradicionalmente femenino e, incluso, criticaban el gesto protector hacia esta empresaria del personaje que representaba a la marca, gesto que no mostraba en la versión masculina de la pieza. En cambio, la publicidad que construye una imagen de consumidora moderna, informada, experta, luchadora y con aspiraciones que van más allá de su rol de ama de casa es muy bien acogida aunque venda detergentes, aceites 0 accesorios para el hogar. Si esta incluye aspectos que redefinen el rol masculino en la pareja y el hogar, su aceptación se vuelve viral en las redes sociales ${ }^{17}$.

Sin embargo, existen aún importantes trabas y tensiones no resueltas para que en el Perú podamos hablar de igualdad de género. A pesar de su empuje y de sus aspiraciones, la mayoría de mujeres no accede aún a la autonomía económica: todavía pocas mujeres de estas nuevas clases medias logran la capacitación suficiente para acceder a los puestos de trabajo más calificados $y$, cuando lo logran, sus remuneraciones no se equiparan a las de los hombres $^{18}$. Y, a pesar del protagonismo de algunas mujeres en el ámbito político, la representatividad femenina es muy baja tanto en las instancias nacionales como en las locales ${ }^{19}$.

Pero uno de los ámbitos de mayor tensión no resuelta en nuestro país es la falta de autonomía de las mujeres sobre su propio cuerpo. En las zonas urbanas, un tercio de las mujeres han sufrido algún tipo de violencia, existe todavía una demanda de métodos anticonceptivos no cubierta y el porcentaje de embarazos adolescentes no se ha reducido, incluso ha aumentado en los últimos años ${ }^{20}$.
Además, muchas de estas mujeres, con restricciones económicas y principales víctimas de la inseguridad ciudadana, se ven tentadas por propuestas asistencialistas y autoritarias. Así, en el proceso electoral reciente, estas fueron los elementos centrales de la candidatura de Keiko Fujimori, que logró mayor empatía con las mujeres, particularmente las de los sectores menos favorecidos ${ }^{21}$.

\section{Conclusión}

Estas experiencias recogidas en experiencias de investigación de mercado nos permiten observar, en la vida cotidiana, este arduo camino hacia la modernidad y el progreso en un entorno de débil institucionalidad, con avances todavía insuficientes en la inclusión y la igualdad, que vive nuestro país.

17 La página web de una tienda de artículos para el hogar incluye una sección de consejos para los padres primerizos con un tono lúdico y autopeyorativo que genera adhesión en esta generación.

18 A nivel nacional el ingreso promedio de las mujeres en 2014 representaba solo el 70,3 \% del de los hombres. (Fuente: INEl, 2015).

19 En el periodo 2011-2016, de los 130 parlamentarios solo 28 fueron mujeres; en los gobiernos locales encontramos 69 alcaldesas frente a 1731 alcaldes, así como 2783 regidoras frente a 7405 regidores. (Fuente: INEI, 2015).

20 El embarazo adolescente afecta a un 14,6 \% de mujeres entre los 15 y los 19 años (INEI, 2015).

21 El $44 \%$ de los votos por Keiko Fujimori en el último proceso electoral fueron de mujeres y el $36 \%$ de hombres. La principal razón del $33 \%$ de los votantes por Keiko Fujimori fue el hecho de que era mujer y la del $23 \%$ su propuesta de "mano dura" ante la inseguridad ciudadana (Ipsos-Perú, encuesta electoral 17 de abril de 2016). 


\section{Bibliografía}

Arellano, R. (21 de junio del 2015). Rolando Arellano. ¿Qué tan grande es la clase media en el Perú [entrevista]. Semana Económica. Recuperado de http://semanaeconomica.com/article/economia/macroeconomia/163032-arellanomarketing-que-tan-grande-es-la-clase-media-en-el-peru/

Augé, M. (1992). Non-lieux. Introduction à une anthropologie de la surmodernité. París: Seuil, La Librairie du xxI siècle.

Fernández-Maldonado, E., y Navarro, D. (2016). ¿Protestas o movimientos sociales? Los casos de Keiko No Va y Peruanos contra el TPP. En M. Toche (comp.), Perú hoy. Ni gran transformación ni hoja de ruta (pp. 157-173). Lima: Desco.

Giddens, A. (1990). Consecuencias de la modernidad. Madrid: Alianza Editorial.

INEI. (diciembre del 2015). Perú. Brechas de género 2015. Avances hacia la igualdad entre mujeres y hombres. Lima: Instituto Nacional de Estadística. Recuperado de https://www.inei.gob.pe/media/MenuRecursivo/publicaciones_digitales/Est/Lib1309/Libro.pdf

Jaramillo, F., y Zambrano, O. (2013). La clase media en Perú: cuantificación y evolución reciente. Lima: Banco Interamericano de Desarrollo. Recuperado de https://publications.iadb.org/bitstream/handle/11319/5940/La_clase_media_en_Peru_final2.pdf?sequence=1

Moraña, M. (2007). Los estudios latinoamericanos en la encrucijada. Entrevista a Mabel Moraña. Itinerarios. Revista de estudios lingüísticos, literarios, históricos y antropológicos, (5), 9-31. Recuperado de http://itinerarios.uw.edu. pl/wp-content/uploads/2014/12/01_entrevista_Morana.pdf

Sanahuja, J. A. (2015). Las nuevas geografías de la pobreza y la desigualdad y las metas de desarrollo global post2015. Madrid: Instituto Complutense de Estudios Internacionales. Recuperado de http://www.ceipaz.org/images/ contenido/4.Sanahuja.pdf

Torres, A. (24 de junio del 2015). Alfredo Torres. ¿Cuán grande es la clase media en el Perú? [entrevista]. Semana Económica. Recuperado de http://semanaeconomica.com/article/economia/macroeconomia/163030-ipsos-quetan-grande-es-la-clase-media-en-el-peru/

Tristán, F. (2003). Peregrinaciones de una paria, 1833-1834. Arequipa: Ediciones del Lector. 